\title{
Interactive comment on "Impact of particle number and mass size distributions of major chemical components on particle mass scattering efficiency in urban Guangzhou of South China" by Jun Tao et al.
}

Jun Tao et al.

leiming.zhang@canada.ca

Received and published: 10 May 2019

The comment was uploaded in the form of a supplement:

https://www.atmos-chem-phys-discuss.net/acp-2018-1367/acp-2018-1367-AC1-

supplement.pdf 